Asking Big: Creating a Culture of Support for Academic Mothers' Advocating in Times of Crisis

Ashley Bender and Jackie Hoermann-Elliott

Texas Woman's University 


\begin{abstract}
This essay brings into focus institutional inequities faced by academic parents that stem from the systematic socialization of women to remain silent about their professional and personal needs under ideal circumstances and even more so in times of crisis. As a result of the COVID-19 pandemic's changing higher education policies daily, we argue there has never been a better time for us to ask for more when academic women, especially those identifying as mothers, are suffering professionally and personally. We trace key cultural insights and recent research regarding how the global pandemic has increased the strain that academic mothers feel, particularly BIPOC mothers, before calling on readers to reclaim their right to advocate on behalf of their and their families' needs. We conclude by defining the culture of asking we seek to foster at our own institution and make recommendations for how readers might "ask big" at their home institutions.
\end{abstract}

Keywords: faculty women, COVID-19, BIPOC women, academic mothers, parental leave, advocacy, support 


\section{Asking Big: Creating a Culture of Support for Academic Mothers' Advocating in Times of Crisis}

On a Tuesday afternoon in November 2020, we made "the big ask," the one no one wants to make but many faculty members and graduate students who identify as mothers have had to consider at some point in their careers: asking for a university parental leave policy. ${ }^{1}$ Two members of our campus affinity group, Maintaining Motherhood in Academia, virtually met with our Chancellor, Provost, and Vice President of Student Life to ask for an amendment to existing sick leave policies to include paid parental leave. We knew full well there were a number of barriers these most powerful campus leaders could not lift. We were anchored tightly to a past precedent of ongoing conversations, follow-up asking, and even meeting with elected officials. Congresspersons, our Chancellor warned us, would be unlikely to fund a collective need as important as parental leave, especially in a time of crisis such as the COVID-19 pandemic, when universities in Texas were returning money to the state. And yet, with all the odds stacked against us, we recognized this crucible moment as an important opportunity to ask anyway.

In this article, we argue for radical acceptance and reclamation of women's right to ask for unsupported needs in academia, even in times of crisis. To be clear, we are not saying women are to blame for not asking enough, nor are we shaming them into asking more. Instead, we aim to call attention to the ways that academics who identify as women-especially mothers; Black, Indigenous, People of Color (BIPOC); and women working in STEM fields - hesitate to advocate on behalf of their needs and how this lack of advocacy points to larger systemic issues, namely policy barriers or lack of policies as well as a resistance to self-advocacy. Our opening

\footnotetext{
${ }^{1}$ We define "mother" in a radically inclusive way, regardless of assigned sex, gender expression, or other relevant identity categories. "Academic mother" is a term we use to include faculty members of all ranks and statuses, including contingent faculty and other non-tenure track faculty. Our use of the term also includes administrators and other non-teaching members of academic communities.
} 
narrative points to the lack of parental leave at our institution as one example that is widely felt across U.S. universities, but many more exist. For our purposes, we will highlight some ways that women resist "asking big" in their daily lives before specifying how women have asked even less of their institutions during the COVID-19 pandemic. We conclude with recommendations for how women might ask more of their institutions in times of crisis as well as how we might increase asking, so all academics can contribute to a culture of asking at their institutions.

\section{The Gendered Context of Asking}

Our ask strategically pushes back against a long history of socialization that forces women to stay silent, that suggests women ask for too much when they ask for policies and support systems that will help them thrive in their professional and private lives. As Iris Bohnet (2003) notes in her Foreword to Women Don't Ask: Negotiation and the Gender Divide, “[s]ocial role theory helps us understand why women are less inclined to initiate negotiations: they have been socialized to hold back, [to] be warm and caring, and conform to the stereotypes we associate with 'a good woman"” (p. ix). Fear of backlash also affects how and for whom women ask, as well as the ways that others perceive their asking (Amanatullah \& Morris, 2010; Bowles et al., 2007; Monroe et al., 2008). For example, advocating for diversity has been shown to negatively affect performance reviews, especially for women and ethnic minority leaders (Hekman et al., 2016); and women's asking is less assertive on their own behalf than when they advocate for others (Amanatullah \& Morris, 2010). Susan Faludi’s (1991) groundbreaking monograph on the subject, Backlash: The Undeclared War Against American Women, called attention to these very issues of "antifeminist backlash" thirty years ago (Faludi, Shames, Piscopo, \& Walsh, 2020), one she acknowledges is still on-going (Gupta, 2020). Further, such 
macro-level backlash legitimates micro-level backlash against individual women who ask. It's no wonder that, for many women, asking elicits fears of — and is met with — retaliation and recrimination. Central to a culture of asking is requesting and expecting clear anti-retaliation policies that institutions actually enforce.

Add to this a fear of the "nothing happens" outcome of asking, and the result is women far too often do not ask, and when they do, they do not ask for nearly enough. We see a hesitation to ask across the spectrum of women's lives, from the most personal—cisheterosexual women are less likely to ask men on dates or to marry them because that's the man's role - to the most professional: women are less likely to negotiate salary when they start a new job, much as they are less likely to ask for raises. Even when women do ask for more, they do so less frequently, and they ask for less - an average of $30 \%$ less than men (Kay and Shipman, 2014). These consequences mean lower lifetime earnings for women. All because women don't ask. The data on salary negotiations are a bellwether for other areas of women's lives. As recently as 2019, a team of anthropologists studying women's participation in academic seminars found that women ask fewer questions during the Q\&A portion of seminars (Carter et al., 2019). Similarly, the Op-Ed Project cites a 2008 Washington Post study that shows 90\% of op-ed pitches were from men, as were $88 \%$ of bylines. Put another way, much as women do not ask for higher starting salaries, they are also not "asking" — that is, pitching — to be published. These dismal findings are matched by the discrepancies between men- and women-identifying academics' publication rates in academic journals, a discrepancy that has grown as a result of the pandemic.

\section{Asking in STEM}


Not only do women struggle to ask for help in the best of times, but the pandemic has made these issues all the more acute for motherscholars working in the fields of science, technology, engineering, and mathematics (STEM). ${ }^{2}$ Now more than before, women in STEM are more vulnerable to professional setbacks or career loss as lack of parental leave or increased childcare demands brought on by the pandemic make an already impossible balancing act all the more difficult to continue. According to Cech and Blair-Loy (2019), nearly half of new mothers working in STEM careers left full-time positions, and 10\% of these mothers accepted part-time work that paid "substantially less" and provided fewer benefits and fewer opportunities for promotion (Cech \& Blair-Loy). It may take some time to fully understand the ramifications of the pandemic on women in STEM's career trajectories, but preliminary findings already suggest a bleak outlook with unequal effects reported in women's weekly research time and an increased need to stop tenure clocks (Cardel et al., 2020; Myers et al., 2020). What's more, many of these findings don't touch on the burden of racism and oppression that compounds the challenges faced by BIPOC mothers trying to care for their families and careers in these tumultuous times.

Almost one year to the day that the World Health Organization declared COVID-19 a pandemic, a group of biologists collaboratively authored an article focused on exposing how the academy disproportionately underserves academic mothers, and they offer advice to faculty mentors, university administrators, scientific societies, publishers, and funding agencies on how to better support women in STEM fields (Fulweiler et al., 2021). This article comes on the heels of other scholars who voiced similar concerns in the ADVANCE Journal first, including Carrie N. Baker (2020), who has documented the structural inequities women with dependent children have faced during the pandemic as childcare demands increased and scholarly productivity

\footnotetext{
2 "Motherscholar" is a term coined by Cheryl E. Matias in 2011 and "refers to the inseparable identities of being both mother and scholar; both-and and not, either-or" (Matias and Nishi, 2017).
} 
decreased. Early on, we saw the effects take shape in lower publication rates for women scholars generally along with some speculation as to these rates being even lower for women who mother (Flaherty, 2020; Minello, 2020; Viglione, 2020). The time is right to think critically about how these inequities stymy women in STEM fields who need to ask for support or build new infrastructures for institutional support systems but feel unsupported in doing so.

\section{Race and Privilege in Asking}

The reality of this data is all the more grim when considering the intersectional identities of many faculty. As scholars, we have witnessed over the last year a growing interest in documenting the challenges women and mothers face in terms of lack of research productivity and career advancement, but few such studies have paid attention to the needs of BIPOC women specifically. Yet for BIPOC faculty, the pandemic has "amplifi[ed] long-standing barriers in the domains of economic inequality, teaching and service, and research demands," which in turn fractures their prospects for professional success in devastating ways (Becker-Blease, 2020). Recent research conducted at a large public research university in the American Southwest shows that Black first-generation women students struggle to persist in their STEM studies more than their White and Asian counterparts (Suárez et al., 2021). And for those who do persist and go on to pursue advanced degrees in STEM fields to become full-time faculty, they are met with regular microaggressions from White and male colleagues on top of additional responsibilities as a result of the pandemic and the Black Lives Matter Movement (Fulweiler et al., 2021; Suárez et al., 2021). Tenisha Tevis (2021) calls attention to these circumstances in her recent article touching on the invisible labor of othermothering that has reached unmanageable levels over the last year. Tevis discusses othermothering largely as the concept pertains to teaching, mentoring, or advising students, but we would be remiss if we did not acknowledge the fact that our BIPOC 
colleagues are also being unfairly tasked with "emotionally charged service activities to confront systemic racism in academia," such as membership on newly formed diversity task forces (Fulweiler et al, 2021). Pre-tenure BIPOC academic mothers face grueling uphill challenges as they encounter additional forms of inequity, including the systemic racism that runs throughout academic systems, a marginalization tied to higher rates of imposter syndrome (Ahmed et al., 2020). The fact is, asking is a privilege that not everyone enjoys equally. Previous work on BIPOC women in science confirms the significant need and benefit in terms of professional advancement to these communities of underrepresented scholars, who could benefit from tenure clock extensions but who might feel judged in asking for them (Wheaton \& Moore, 2019). Reclaiming and, importantly, normalizing the right to ask for support at any time including times of crisis is one way to resist the systems of oppression at work in institutions of higher education.

\section{Working toward Institutional Change}

In response to the COVID-19 pandemic, some academic parents have responded to unsustainable conditions by forming activist caregiver collectives within their institutions, acknowledging that they were hired into "a culture that has either individualized or ignored the concerns of employee caregivers," and they "could no longer wait for long promised improvements" (Raygoza et al., 2020, p. 4). Such collective action has allowed these faculty to ask big by sending to campus leaders a formal letter demanding "immediate policy and practice changes in response to COVID-19 and three demands for the long-term institutionalization of an inclusive family-centered work culture" (Raygoza et al., 2020, p. 5). These actions provide one model that might help faculty-caregivers at other universities to do the same.

While we recognize the give-and-take at the institutional level that is required to create a culture of asking, contributing to this culture affords agency that has been otherwise lacking. We 
define a culture of asking as one in which faculty, staff, and administrators support and encourage women, mothers, BIPOC faculty, and other marginalized groups in their asking of support for unmet needs as opposed to shaming these groups when they advocate for policy changes that would improve the professional and personal well-being of employees. To start, we recommend the following:

Find solidarity early on. As Raygoza et al.'s and our own experiences suggest, identify community groups on campus where individuals interested in pursuing institutional reform can come together to discuss policy changes. Note and track where the greatest need exists or where you have the most resources to advocate for change effectively and persuasively.

Ask to get your foot in the door. As our students learn in many introductory psychology courses, the foot-in-the-door technique demonstrates that small and spaced-out asking leads to slight changes that set the stage for long-term results (Doliński, 2016). We were delighted when our leaders agreed to amend sick leave policies to better support postpartum mothers on our campus. In a year or so, we hope to revisit the issue with upper administration to see if we might make the big ask again.

Prepare for a door in the face. Accept that you may be met with outright rejection that will likely stoke feelings of failure. But remember, failure is part of this process. Research suggests that asking big means frequent rejection, but a repeated "No" does not mean that the no is permanent. Familiarize yourself with the psychology of the door-in-the-face technique, and lean on others in your group when you need to combat feelings of failure (Doliński, 2016).

Create a Culture of Asking. When we unabashedly ask for what we need on a more regular basis, we rally our colleagues to do the same. We must model our asking, be transparent in explaining to our colleagues why we ask for more than we realistically expect to receive less, 
and affirm other faculty and staff when it is their time to ask of us. Asking is both symbolic and social, and to create a culture of asking, we have to start one ask at a time.

We recognize that the previous suggestions focus primarily on what people, individually and collectively at a single institution, might do to advocate for change. However, such approaches need not remain siloed. Actions such as these across institutions, within professional organizations, and in spaces of broader public discourse (e.g., \#academictwitter) can help build solidarity across institutional and disciplinary lines and create momentum for improved equity and improved conditions for asking. We also recognize that the swiftest means to improve cultures of asking and equitable working conditions is for institutions to be proactive not reactive, to enact meaningful policy and structural changes, such as improved representation, equitable leave policies, and even providing childcare grants and other resources academic mothers need in order to disseminate their research effectively (Cohen-Miller, 2020).

The COVID-19 pandemic has created a crucible, one that has pushed faculty, especially academic mothers, especially BIPOC faculty, to their already stretched-thin limits. With working conditions and inequities laid so bare, we argue that now more than ever is the time to ask. If history has proven anything, it's that institutions are unlikely to advocate on our behalf if we don't ask for change. And we need more askers to become leaders: when the people willing to advocate even at lower levels of power take on administrative roles, we have a far greater chance of improving institutional environments.

The simple fact is that, too often, the policies and support we need to ask for are not simple to achieve. Institutional change requires our asking, our administrators' asking, and even our legislators' asking on our behalf. But perhaps we can learn something from the failure of trickle-down economics (Ingraham, 2020): Sometimes, progress and improvement happen by 
trickling up. By changing the culture of asking at our institutions, we pave the way for more change by emboldening others to ask big, too. Investing in a culture of asking has payoff potential that allows us not just to survive, in times of crisis or otherwise, but to thrive. The bottom line is this: supported faculty are productive, healthy, capable faculty. We do our jobs better if we are supported. And all of this starts with asking big. 


\section{References}

Ahmed, A., Cruz, T., Kaushal, A., Kobuse, Y., \& Wang, K. (2020). "Why is there a higher rate of imposter syndrome among BIPOC?” International Socioeconomics Laboratory 1(2), 1-17. doi: https://doi.org/10.5281/zenodo.4310477

Amanatullah, E. T., \& Morris, M. W. (2010). "Negotiating gender roles: Gender differences in assertive negotiating are mediated by women's fear of backlash and attenuated when negotiating on behalf of others." Journal of Personality and SOcial Psychology 98(2), 256-67.

Bohnet, I. (2003). "Foreword." Women don't ask: Negotiation and the gender divide. (Babcock, L. \& Laschever, S. eds.). Princeton University Press.

Baker, C. (2020). “Amplification of structural inequalities: Research sabbaticals during COVID19.” The ADVANCE Journal, 2(2), 1-14. doi: https://doi.org/10.5399/osu/ADVJRNL.2.2.3

Becker-Blease, K. A. (2020). "Ten steps to more equitable academic publishing in the pandemic.” The ADVANCE Journal, 2(2), 1-14. doi:

https://doi.org/10.5399/osu/ADVJRNL.2.2.2

Bowles, H. R., Babcock, L., \& Lai, L. (2007). "Social incentives for gender differences in the propensity to initiate negotiations: Sometimes it does hurt to ask." Organizational Behavior and Human Decision Processes, 101(1), 84-103.

Cardel, M. I. et al. (2020). "Preventing a Secondary Epidemic of Lost Early Career Scientists. Effects of COVID-19 Pandemic on Women with Children." Annals of the American Thoracic Society, 17(11), 1366-1377. doi: https://doi.org/10.1513/AnnalsATS.202006589IP 
Carter, A. J. et al. (2019). "Women's visibility in academic seminars: Women ask fewer questions than men.” PLOS ONE, 14(2). https://doi.org/10.1371/journal.pone.0212146

Cech, E.A. \& M. Blair-Loy. (2019). "The changing career trajectories of new parents in STEM.” Proceedings of the National Academy of Sciences of the United States of America, 116(10), 4182-4187. doi: https://doi.org/10.1073/pnas.1810862116

Cohen-Miller, A. (2020, May 19). "Promoting Equity and Inclusion for Mothers in Academe." Inside HigherEd. https://www.insidehighered.com/blogs/university-venus/promotingequity-and-inclusion-mothers-academe

Doliński, D. (2016). Techniques of social influence: The psychology of compliance. Routledge. Faludi, S. (1991). Backlash: The undeclared war against American women. Crown Publishing Group.

Faludi, S., Shames, S., Piscopo, J. M., \& Walsh, D. M., “A conversation with Susan Faludi on backlash, Trumpism, and \#MeToo.” Signs: Journal of Women in Culture and Society 45(2), 336-345.

Flaherty, C. (2020, April 21). "No room of one's own.” Inside HigherEd. https://www.insidehighered.com/news/2020/04/21/early-journal-submission-datasuggest-covid-19-tanking-womens-research-productivity

Flaherty, C. (2020, August 20). "Something's got to give." Inside HigherEd. https://www.insidehighered.com/news/2020/08/20/womens-journal-submission-rates$\underline{\text { continue-fall }}$

Fulweiler, R. W., Davies S. W., Biddle J. F., Burgin A. J., Cooperdock E. H. G., Hanley T. C., et al. (2021). "Rebuild the Academy: Supporting academic mothers during COVID-19 and beyond.” PLoS Biology 19(3). doi: https://doi.org/10.1371/journal.pbio.3001100 
Hekman, D. R., Johnson, S. K., Foo, M., \& Yang, W. (2106). "Does diversity-valuing behavior result in diminished performance ratings for non-white and female leaders?" Academy of Management Journal 60(2), 771-797. doi: https://doi.org/10.5465/amj.2014.0538

Ingraham, C. (2020, December). "“Trickle-down' tax cuts make the rich richer but are of no value to overall economy, study finds." The Washington Post. https://www.washingtonpost.com/business/2020/12/23/tax-cuts-rich-trickle-down/

Kay, K. \& Shipman, C. (2014). The confidence code: The science and art of self-assurance. Harper Business.

Matias, C. E., and Nishi, N. W. (2017). "ParentCrit epilog." International Journal of Qualitative Studies in Education, 31(1), 82-85.

Minello, A. (2020, April 17). "The pandemic and the female academic." nature. https:/www.nature.com/articles/d41586-020-01135-9

Monroe, K., Ozyurt, S., Wrigly, T., \& Alexander, A. (2008). “Gender equality in academia: Bad news from teh trenches, and some possible solutions." Perspectives on Politics, 6(2), 215-233. doi:https://doi.org/10.1080/09518398.2017.1379625

Myers, K.R. (2020). "Unequal effects of the COVID-19 pandemic on scientists." Nature human behavior. 4. 880-883. doi: https://doi.org/10.1038/s41562-020-0921-y

Op-Ed Project. (n.d.) Op-ed writing: Tips and tricks. Retrieved January 10, 2021, from https://www.theopedproject.org/oped-basics

Raygoza, C., Viola, M. J., Klein, E. B. \& León, R. J. (2020) “From private struggle to parentscholar solidarity: Collective organizing during a pandemic to humanize the academy." 8. Transcontinental Human Trajectories. doi: 10.25965/trahs.3122. 
Suárez, M.I., Dabney, A.R., Waxman, H.C., Scott, T.P., Bentz, A.O. (2021). “Exploring Factors that Predict STEM Persistence at a Large, Public Research University.” International Journal of Higher Education 10(4). doi: https://doi.org/10.5430/ijhe.v10n4p161

Tevis, Tenisha. (2020). "By obligation and by choice: Taking on extra responsibilities during COVID-19 and the Black Lives Matter Movement." The ADVANCE Journal, 2(2). doi: https://doi.org/10.5399/osu/ADVJRNL.2.2.11

Viglione, G. (2020, May 20). “Are women publishing less during the pandemic? Here's what the data say." nature. https://www.nature.com/articles/d41586-020-01294-9

Wheaton, D. \& Moore, L. (2019). “ADVANCING Women of Color in STEM through Meaningful Mentoring: Key Observations from the Jackson State University ADVANCE Institutional Transformation Project." The ADVANCE Journal, 1(2). doi: https://doi.org/10.5399/osu/ADVJRNL.1.2.5 